\title{
Research on Establishing City Low Carbon Economy Evaluation Theory Model
}

\author{
Xiao Wei*
}

\author{
College of Civil Engineering and Architecture, Chongqing Jiaotong University, Chongqing 401122, China
}

\begin{abstract}
To explore the method of creating a theoretical model of urban low-carbon economy evaluation, and analyze the development status and level of low carbon economy in cities in the middle and lower reaches of Yangtze River; Method To introduce the basic theory of low-carbon economy, the principle and the technical route for creating the evaluation system of urban low-carbon economy, develop 3 layers of 5 categories of 18 evaluation indicators, conduct weighted calculation using Delphi method, analytic hierarchy process(AHP), fuzzy evaluation method and fuzzy AHP method, investigate into 7 cities, such as Shanghai, Nanjing in the middle and lower reaches of Yangtze River, and evaluate the urban low-carbon economic status using the created models; Results The evaluation result shows that at present China has many cities at "medium to high carbon economy" or "high carbon economy" types. The development level of low-carbon economy lagged behind many western countries; Conclusion It is a most efficient pathway to improve the present low-carbon economic level by vigorously developing the low-carbon technology, developing the low-carbon environmental education and promoting the low-carbon concept.
\end{abstract}

Keywords: AHP, delphi method, evaluation indicator, evaluation system, fuzzy AHP process, fuzzy evaluation method, "highcarbon economic" city, low-carbon economy.

\section{INTRODUCTION}

With the rapid development of science and technology, under-expectation and unfavorable precaution of human over the high development of science and technology, especially the negative impact of highly developed industry have led to the 3 global crises, including resource shortage, environmental pollution and ecological damage, which have serious impact on contemporary society [1]. The environmental pollution refers to the behavior posing harm to the environment by natural or artificial release of harmful substances into the environment beyond the self-cleaning ability of the natural environment under the national conditions $[2,3]$. As the manmade factors change the environmental components or status, the environmental quality declines, thus disrupting and disturbing the normal ecological system and human's production and living conditions. The studies of Intergovernmental Panel on Climate Change (IPCC) found that, in one century from 1906 to 2005 , the global average surface temperature rose $0.74^{\circ} \mathrm{C}$ and is expected up to 1.1 to $6.4^{\circ} \mathrm{C}$ by the end of this century and the initiator of global warming is the excessive carbon emissions. Upon into the twenty-first century, the human life style has underwent a huge change; the wind energy, solar energy, hydropower, nuclear energy, geothermal energy and other renewable resources have been developed and utilized, the human being has advanced from traditional to modern industrial civilization gradually [4]. However, with the growing global population in amount and increasing economic size, the people have been continuously realizing the environmental problems and aftermaths caused by the use of conventional energy sources, such as fossil energy; the hazards with waste gas pollution, photochemical smog, water pollution and acid rain; and severe consequences of unhealthy life style and the use of conventional energy. Against this context, the "low carbon economy" concept rises in the response to the proper times [5].

Low carbon economy (LCE) refers to an economic development form to optimally reduce the consumption of high-carbon energies, such as oil and coal, reduce the greenhouse gas emission and reach a win-win of economic \&social development and ecological \& environmental protection by using a variety of means, such as technological innovation, regulatory system innovation, industrial transformation, new energy development, etc under the guidance of sustainable development philosophy. Proverbially, the carbon dioxide has three key sources, namely thermal power emissions, vehicle exhaust and building emission $[6,7]$. The low carbon economy is characterized in reducing the greenhouse gas emissions and constructing an economic development system based on low energy consumption and low pollution. The low carbon economy includes low carbon energy system, low carbon technologies and low carbon industrial system [8]. The low carbon energy system refers to the reduction of carbon dioxide emissions by developing the clean energy, such as wind energy, solar energy, nuclear energy, geothermal energy and biomass alternatives instead of fossil energies, such as coal, oil, etc [9]. With the "low carbon" discourse, the jargons of "low carbon society", "low carbon city", "low-carbon supermarket", "low carbon campus", "low carbon transport", "low carbon environmental protection", "low carbon network", "low carbon community" have 
appeared- all walks of life rush to label themselves as "low carbon" that has become a kind of fashion [10, 11].

In the present paper, with the cities in the middle and lower reaches of Yangtze River as the research objects, the development status and level of the low carbon economy was investigated into with an aim to create an evaluation model of urban low carbon economy and make a reasonable evaluation on the low carbon economy in cities in the middle and lower reaches of Yangtze River.

\section{CRITERIA FOR CREATING THE EVALUATION SYSTEM OF URBAN LOW CARBON ECONOMY}

The primary task of low carbon economy is to develop the sustainable development strategy and be particular about the win-win associated pattern of environmental-friendly and economic development. In order to create a scientific, reasonable, systematic evaluation model for urban low carbon economy, we must firstly understand the components and meanings of low carbon economy deeply. So far, many Chinese and foreign scholars have studied the low carbon economy. The principle of creating an evaluation system of low carbon economy is as below:

1) Principle of combining conciseness and representativeness. The evaluation system of low carbon economy should be a kind of framework that is easily understood and accurately reflect the meanings of the evaluation system of low carbon economy. The system also varies with the regions. As the present paper researched the evaluation system of low carbon economy in cities in the middle and lower reaches of Yangtze River, the comprehensive indicators combining the conciseness and representativeness should be used.

2) Principle of systematic optimization and hierarchy. The goal of low carbon economic system is to create a set of new urban sustainable development pattern with low pollution, low energy consumption, low emissions and low carbon economy. The evaluation indicator of urban low carbon economy not only wholly reflects the urban economic development, but also reflects the environmental pollution incidental to the urban economic development. Therefore, a set of systematic and hierarchical indicators must be set up.

3) Principle of combining science and feasibility. The evaluation indicators of low carbon economy must rely on a sound theoretical support and the existing evaluation system of urban low carbon economy at home and abroad. It is necessary to set up a set of scientific, effective, feasible and comprehensive evaluation indicators of urban low carbon economy.

4) Principle of combining dynamics and statics. It is a dynamic process to create the evaluation system of low carbon economy, a constantly developing process, and also within a short term, a steady static process. During the gradual forward development process, the evaluation system of low carbon economy should be a process of combining the dynamics and statics.

5) Principle of combining the qualitative analysis and quantitative calculation. The qualitative analysis is a macro understanding at indicator analysis so that the evaluation indicators can be the quantitative indicators as far as possible. The evaluation system of low carbon economic should have both features of qualitative analysis and quantitative calculation,

It is known from the definition of low carbon economy that it is a complex system integrating the economic system, technological system, social system and environmental system. According to some scholars' researches, the composite theory can be made the guidance for creating a low carbon economy. The present paper investigated into the cities in the middle and lower reaches of Yangtze River and created the framework graph as illustrated in Fig. (1).

In above graph, the first layer is a target layer, i.e. the evaluation system layer to be reached finally; the second layer is a criteria layer including the low carbon economy system, low carbon technologic system, low carbon social system, low carbon environmental system and low carbon concept system; the third layer is an indicator layer, i.e. the criteria in the second layer are evaluated using the different indicators. It includes the system evaluation indicators. Above 3 layers of indicator system framework can reflect the low carbon economy level of the whole city more comprehensively.

\section{CREATING THE EVALUATION INDICATOR SYSTEM OF URBAN LOW CARBON ECONOMY}

By learning from the research at home and aboard, the author thought the criteria layer of the evaluation system of low carbon economy must be divided into 5 systems, i.e. low carbon economy system, low carbon technological system, low carbon social system, low carbon environmental system and low carbon concept system. Additionally, the paper has itemized 5 systems.

Economy, as a symbol of the urban development level of a city, has a critical status in the evaluation system of low carbon economy. Among the evaluation indicators of low carbon economy, the paper selects the indicators: resident's per capita GDP, resident's income, resident's disposable income, urban opening-up level and foreign trade import quota; the low carbon technology is also a major factor in evaluation system of low carbon economy as the carbon dioxide emission is an important criterion for weighing the urban low carbon economy level. The selected evaluation indicators in low carbon technological system must reflect the substantial effort of a country or a region to reduce the carbon emission. Therefore, the paper selected the indicators from the low carbon technological system: proportion of clean energy, repeated utilization rate of industrial waste, proportion of low energy consumption buildings, cleaning ratio of urban industrial waste, resident's wastewater treatment rate; as the evaluation system of low carbon economy is a social evaluation system, the impact of various social factors should be taken into account in setting the evaluation indicators. The paper selected the social system indicators: engel coefficient, urbanization progress and rate, ratio of urban bus to citizens, Gini coefficient, etc.; the low carbon environmental system and low carbon concept system in the evaluation system of low carbon economy are auxiliary systems. The present paper selected the major indicators: forest coverage rate, per capita green area, urban greening area; and 
the indicators in theoretic systems were selected based on the social questionnaire survey.

The weight of evaluation indicator is a numeral indication of relative significance of each indicator in the evaluation indicator system. Whether the weight is set rightly and reasonably has a key influence on the regional development level of low carbon economy. Therefore, the process to determine the weight becomes a core link during the comprehensive evaluation process. The weight must be assigned according to the influence level of indicators on the target layers since the evaluation indicators vary with the significance in the indicator system. Based on evaluation indicator system created as in Fig. (1), the selected indicators were weighted using the Delphi, AHP, fuzzy evaluation method and fuzzy AHP. The calculation results are shown in Table $\mathbf{1}$.

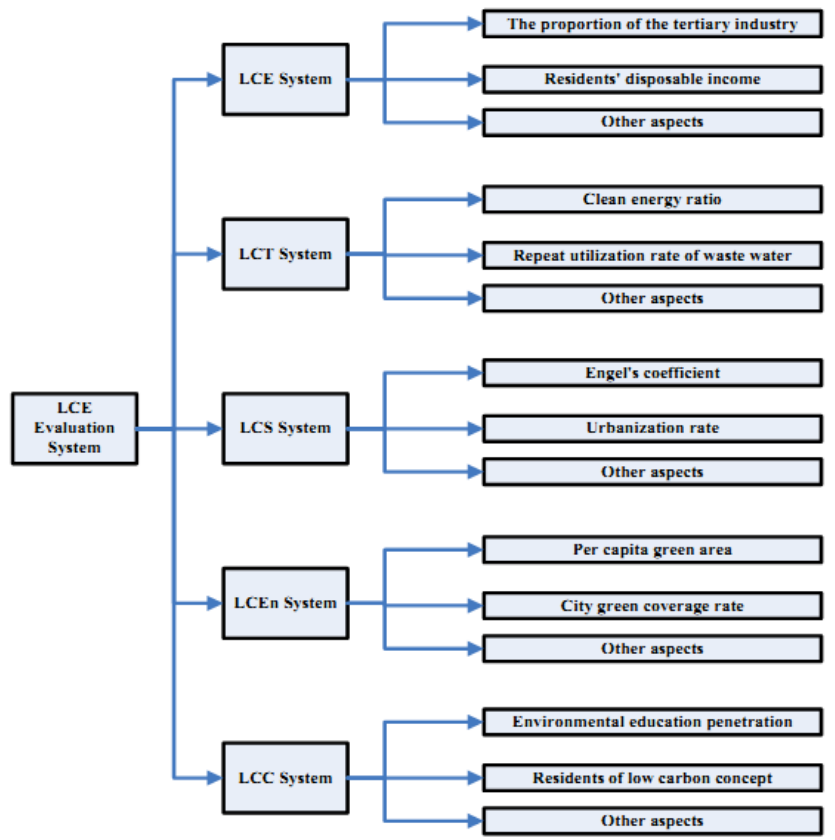

Fig. (1). Technical route graph of evaluation system of urban low carbon economy.

In the present study, the hierarchical evaluation criteria for low economy are set up with the advisory experts. The criteria refer to the evaluation standard in developed countries, i.e. the comprehensive evaluation scores are calculated for urban low carbon economy using the indicator synthesis method. The city is referred to as a "low carbon economy" type when the comprehensive evaluation indicator is greater than 1.165; the city is referred to as a "medium low carbon economy" type when the comprehensive evaluation indicator is between 1 1.165; the city is referred to as a "medium carbon economy" type when the comprehensive evaluation indicator is between $0.875 \sim 1$; the city is referred to as a "medium high carbon economy" type when the comprehensive evaluation indicator is between 0.675 0.875; the city is referred to as a "high carbon economy" type when the comprehensive evaluation indicator is between 0.42 0.675; and the city is referred to as an "ultra-high carbon economy" type when the comprehensive evaluation indicator is less than 0.42 .

\section{RESEARCH ON APPLICATION CASES}

The relative significance of 5 systems can be quantitatively calculated from Table $\mathbf{1}$. The weights of low carbon economy system, low carbon technological system, low carbon social system, low carbon environmental system and low carbon concept system are $0.256,0.335,0.171,0.119$ and 0.119 respectively. The low carbon environmental system and low carbon conceptual system can be integrated as a system, i.e. the low carbon environmental and conceptual system with a weight of 0.238 . If the indicator evaluation indicators of low carbon economy system, low carbon technological system, low carbon social system, and low carbon environmental and conceptual system are $X_{1}, X_{2}, X_{3}$ and $X_{4}$ respectively in the evaluation system of low carbon economy, the evaluation scores of low carbon economy can be calculated using the linear weighted method. The calculation formula is as follows:

$Y=0.256 * X_{1}+0.335 * X_{2}+0.171 * X_{3}+0.238 * X_{4}$

where, $X_{i}$ is an indicator matrix of an indicator layer. In actual calculation, $\mathrm{X}_{\mathrm{i}}$ is often calculated as a whole indicator. See Equation 2 for the $\mathrm{X}_{\mathrm{i}}$ calculation process:

$X_{i}=\frac{1}{n} \sum_{j=1}^{n} x_{j}$

Accordingly, the comprehensive indicator for development level of low carbon economy can be calculated for various cities. The present paper investigated into 7 cities: Shanghai, Suzhou, Wuxi, Zhenjiang, Nanjing, Wuhan, Hefei in the middle and lower reaches of Yangtze River, using questionnaire survey, data query and Delphi, etc. the scoring results for 7 cities are shown in Table 2.

The evaluation scores of low carbon economy in 7 cities are easily calculated according to Equation 1 . The results are shown in Fig. (2).

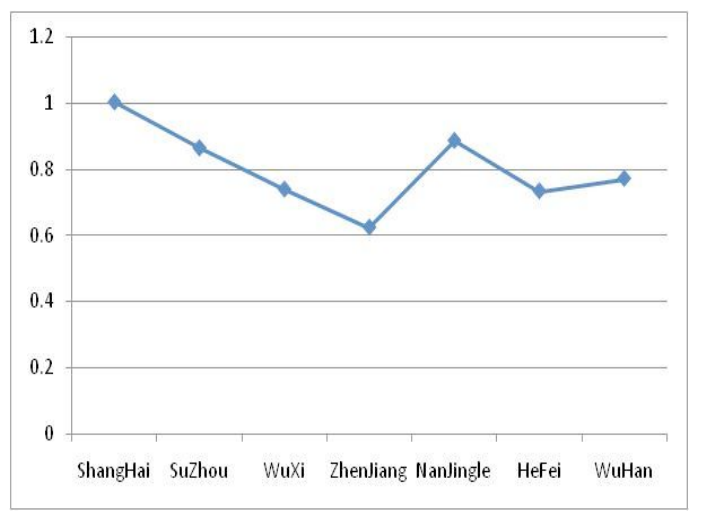

Fig. (2). Comparison of evaluation results of low carbon economy in cities in the middle and low reaches of the Yangtze River.

It is easily found from above figure that, among the surveyed cities, mere Shanghai belongs to "medium low carbon economy" type; Suzhou and Nanjing to the "medium carbon economy" type; the rest to "medium high carbon economy" type. By ordering the comprehensive evaluation weights, the rank of 7 cities in low carbon economy development level is: Shanghai $>$ Nanjing $>$ Suzhou $>$ Wuxi $>$ Zhenjiang $>$ Hefei $>$ Wuhan. 
Table 1. The evaluation indicator system of low carbon economy.

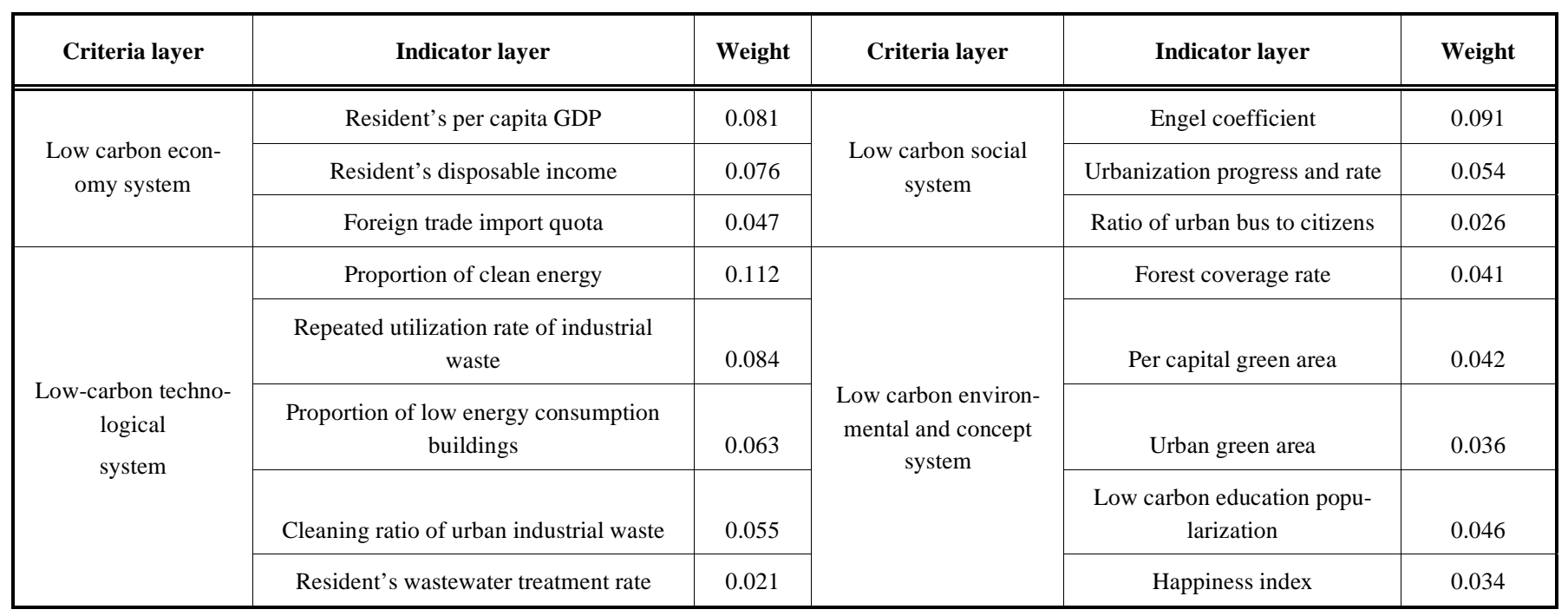

Table 2. Scoring results of comprehensive evaluation indicator of urban low carbon economy.

\begin{tabular}{|c|c|c|c|c|}
\hline City & Low carbon economy system & Low carbon technology system & Low carbon social system & Low carbon environmental and conceptual system \\
\hline \hline Shanghai & 1.8745 & 0.7142 & 1.4152 & 0.1741 \\
\hline Suzhou & 1.4952 & 0.5641 & 1.5321 & 0.1247 \\
\hline Wuxi & 1.3606 & 0.5214 & 1.1234 & 0.0987 \\
\hline Zhenjiang & 1.0621 & 0.4367 & 1.0002 & 0.1441 \\
\hline Nanjing & 1.5454 & 0.5941 & 1.4926 & 0.1516 \\
\hline Hefei & 1.3221 & 0.4986 & 1.1128 & 0.0841 \\
\hline Wuhan & 1.4512 & 0.5309 & & 0.1328 \\
\hline
\end{tabular}

\section{CONCLUSION}

China's cities in the Yangtze River basins are more developed. Their development level shows a rising trend from west to east. The above investigation results show that many developed cities in our country are still at the "medium high carbon economy" type or "high carbon economy" type. There is still a gap between them and those in the European and American countries. However, with China's economic and technological growth and increasing awareness of environmental protection in recent years, the researches on low carbon economy have been deepened and extended gradually in China. For example, in July, 2007, Premier Wen Jiabao attended and deployed the work in response to the climate change, organized and fulfilled the energy-saving emission reduction work; on 28th, January, 2008, WWF launched the "China's low carbon urban development projects" officially; in August, 2010, the National Development and Reform Commission piloted to construct the low carbon industries in 8 cities, 5 provinces.

In order to investigate into the development status and level of low carbon economy in cities in the middle and lower reaches of the Yangtze River, the author visited many relevant departments from February, 2013 to October, 2014, referred to the related data files, evaluated the questionnaire for low carbon economy in Shanghai, Suzhou, Wuxi, Zhenjiang, Nanjing, Hefei and Wuhan, formulated 3 layers of 18 evaluation indicators by combining the researches at home and abroad and calculated the evaluation indicators of low carbon economy using the linear weighted method. The calculation results show that a majority of cities are at "medium high carbon economy" type or "high carbon economy" type. The typing results are far below the level in the developed countries. Additionally, we found during the survey that the indicators of low carbon economy and low carbon social awareness are rising commonly, but the low carbon technology, environment and concept are to be developed. Thus, it is a most efficient pathway to improve the present lowcarbon economic level by vigorously developing the lowcarbon technology, developing the low-carbon environmental education and promoting the low-carbon concept.

\section{CONFLICT OF INTEREST}

The authors confirm that this article content has no conflict of interest. 


\section{ACKNOWLEDGEMENTS}

Declared none.

\section{REFERENCES}

[1] Y. X. Liu, On creating and evaluation method of indicator system of urban low carbon economy. Beijing: Capital University of Economics and Business, 2013.

[2] J. Ma, L. Zhou, and W. Li, "Creating of evaluation indicator system of urban low carbon economy-based on the examples of low carbon development status in 6 eastern coastal provincial cities", Science \& Technology Progress and Policy, vol. 27, no. 20, pp. 165-168, 2010.

[3] J. H. Pan, G. Y. Zhuang, and Y. Zheng, "The conceptual identification and core element analysis of low-carbon economy", International Economic Review, no. 4, pp. 89-91, 2010.

[4] M. Dalton, B. O'Neill, A. Prskawetz, L. W. Jiang, and J. Pitkin, "Population aging and future carbon emissions in the United States", no. 30, pp. 642-675, 2008.

[5] X. Y. Li and L. Deng, "To explore the comprehensive evaluation of urban low carbon economy-based examples of municipalities directly under the central government", Modern Economic Research, no 2, pp. 82-85, 2010.

[6] W. T. Zhang, "On the comprehensive evaluation of low carbon economy in central cities in Yangtze River economic belt". Wuhan: Wuhan University of Technology, 2013.

[7] K. Shimada, Y. Tanaka, K. Gomi, and Y. Matsuoka, "Developing a long-term local society design methodology towards a low-carbon economy: an application to shiga prefecture in Japan”, Energy Policy, vol. 35, no. 9, pp. 4688-4703, 2007.

[8] C. F. Lee, S. J. Lin, C. Lewis, and Y. F. Chang. "Effects of carbon taxes on different industries by fuzzy goal programming: a case study of the petrochemical-related industries", Energy Policy, vol. 35, no. 8, pp. 4051-4058, 2007.

[9] C. D. Holtbriigge and T. Schuster, "Competitive advantage of German renewable energy firms in India and China: an empirical study based on porter's diamond", International Journal of Emerging Markets, vol. 7, no. 2, pp. 191-214, 2012.

[10] J. F. Fu, G. Y. Zhuang, and Q. X. Gao, "Conceptual identification and creating of evaluation indicator system of low carbon economy", Chinese Journal of Population Resources and Environment, vol. 20, no. 8, pp. 38-43, 2010

[11] B. Y. Wei, X. Q. Fang, and Y. Wang, "On carbon emission of Chinese international trade based on the analysis of input and output", Journal of Beijing Normal University(Natural science edition), vol. 45, no. 4, pp. 413-419, 2009.

[12] L. Gaiabova and G. Ahonen, "Is intellectual capital-based strategy market-based or resource-based on sustainable strategy in a knowledge-based economy", Journal of Human Resource Costing \&amp Accounting, vol. 15, no. 4, no. 313-327, 2011.

[13] M. Marufhossain, M. H. Rahman, and K. Park, "Manifestations of climate change impacts affecting socio-economy in Bangladesh: Looking through the framework of sustainable development", International Journal of Climate Change Strategies and Management, vol. 21, no. 2, pp. 180-190, 2010.

(C) Xiao Wei; Licensee Bentham Open.

This is an open access article licensed under the terms of the (https://creativecommons.org/licenses/by/4.0/legalcode), which permits unrestricted, noncommercial use, distribution and reproduction in any medium, provided the work is properly cited. 